\title{
Initial Feasibility Study to Drill and Core the Ocean Mantle
}

\author{
by Nicolas Pilisi and Bill Whitney
}

\section{Introduction}

An initial feasibility study (Pilisi and Whitney, 2011) of drilling through the Mohorovičić discontinuity (Moho) into the oceanic mantle specifically focused on future requirements for planning, drilling and coring a hole $500 \mathrm{~m}$ into the oceanic mantle from three candidate locations in the Pacific Ocean (Cocos Plate, Baja California, and offshore Hawaii). The study points out some of the critical issues that need to be resolved before embarking upon such a challenging project. It was conducted on the basis of data provided by the Integrated Ocean Drilling Program-Management International (IODP-MI), the Center for Deep Earth Exploration (CDEX) operating the drilling vessel Chikyu within IODP, public domain information, and past experience that Blade Energy Partners (hereafter mentioned as "Blade"; http://www.blade-energy.com/) has had with frontier projects in the offshore deepwater oil and gas and geothermal industries.

\section{Project Challenges}

The challenges associated with drilling/coring a hole through the Moho and into the mantle have been understood for some time and have been comprehensively discussed in previous IODP and legacy program reports and documents.

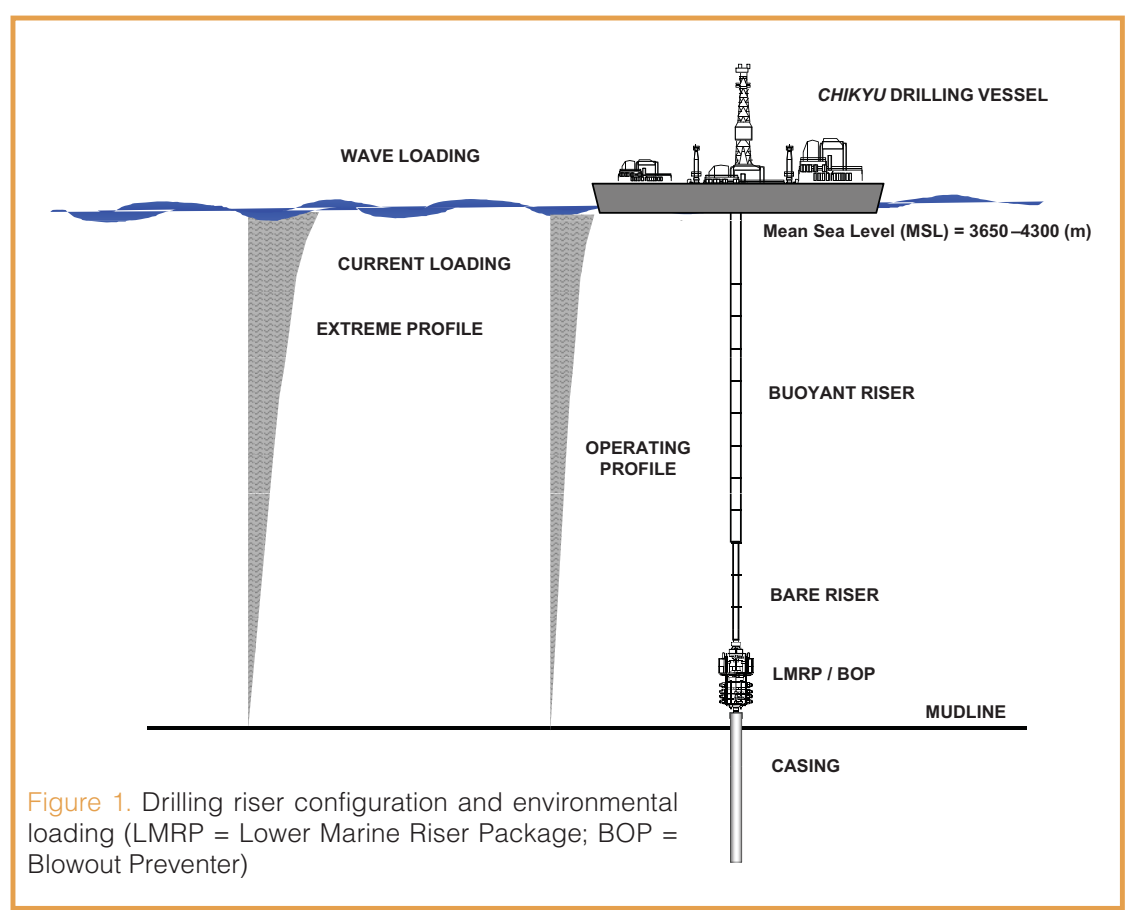

Blade's focus was therefore not to re-examine the issues, but rather to evaluate them in terms of current and trending technologies in oilfield and geothermal industries to determine how difficult it will be to resolve the issues. The obvious constraints for this project versus "normal" offshore drilling operations are the extreme water depths where operations need to be conducted, the extreme high temperatures present in very hard igneous rocks that push the limit of all the drilling, and coring tools that are routinely used in less demanding environments. The main challenges that need to be overcome include the following:

1. Riser drilling in ultra-deepwater environments with water depths around $4000 \mathrm{~m}$ (which will set a new world record)

2. Drilling and coring in very high temperature igneous rocks with bottom-hole temperatures that are estimated to be as high as $250^{\circ} \mathrm{C}$

3. Drilling and coring a very deep hole having a total drilled/cored interval of up to $6700 \mathrm{~m}$ in the oceanic crust below the Pacific Ocean seafloor

\section{Feasibility Study Results}

The study (Pilisi and Whitney, 2011) included a detailed analysis of the drilling riser design requirements for the environmental conditions expected at the three candidate locations (Fig. 1). The analysis looked at the operational envelope of the current riser configuration on riser equipped drillship Chikyu (Fig. 2), as well as alternative designs for five other possible riser configuration options (current riser with lighter buoyancy modules, titanium riser, slim riser, hybrid riser, current riser with two additional riser tensioners). The analysis concluded that there are existing available technologies, equipment, and materials in the ultra-deepwater industry that should enable the Chikyu to conduct operations in the expected water depth range (3650-4300 m) at the candidate locations.

The study also looked at different well design scenarios in order to further define the key operational and design issues that will need to be resolved prior to drilling into 
the mantle well. Most of the information about the downhole conditions is presently unknown. Therefore, assumptions had to be made about the fundamental downhole conditions that impact well design. For example, the assumed downhole temperature profiles for the candidate locations were based on previous models of formation burial depth and age provided by IODP-MI and from operations conducted at the Cocos location in the IODP Hole 1256D (Alt et al., 2007). In addition, a downhole pressure estimate was developed in order to develop a casing program. In most deepwater wells the presence of abnormal pressure is a fundamental criterion for determining casing points and the drilling mud density required to reach total depth. Since the Moho wellbore is expected to be entirely normally pressured (1.03 specific gravity [SG]), abnormal pressure is not an issue. Therefore, the selection of casing points and mud weights will be based on wellbore stability considerations. For example, if the mud weight is too low, the hole will essentially collapse due to a compressive shear failure in the rock. However, a trade-off must be made between the allowable mud weights and the number of casing strings that are used. There are only so many casing strings that can fit in a well; running multiple strings is time-consuming and costly, and it complicates the geometry of the well. It is certainly advantageous to minimize the number of casing strings used for the Moho well, if only to minimize the sizes of the rotary core barrel bits that would need to be developed.

This effort resulted in the development of a base case wellbore configuration that assumes that significant parts of the wellbore will need to be cased off in order to reach total depth (Fig. 3). With the wellbore thus defined, the expected downhole circulating temperature profiles could be modeled, and the issues around the design of a drill string could be examined. It was determined that the circulating temperatures exceed the temperature ratings of most downhole tools that are commercially available today. Increasing the downhole tools' temperature rating is a significant issue that will need to be addressed. On the other hand, it was determined that the Moho wells could be drilled today with a

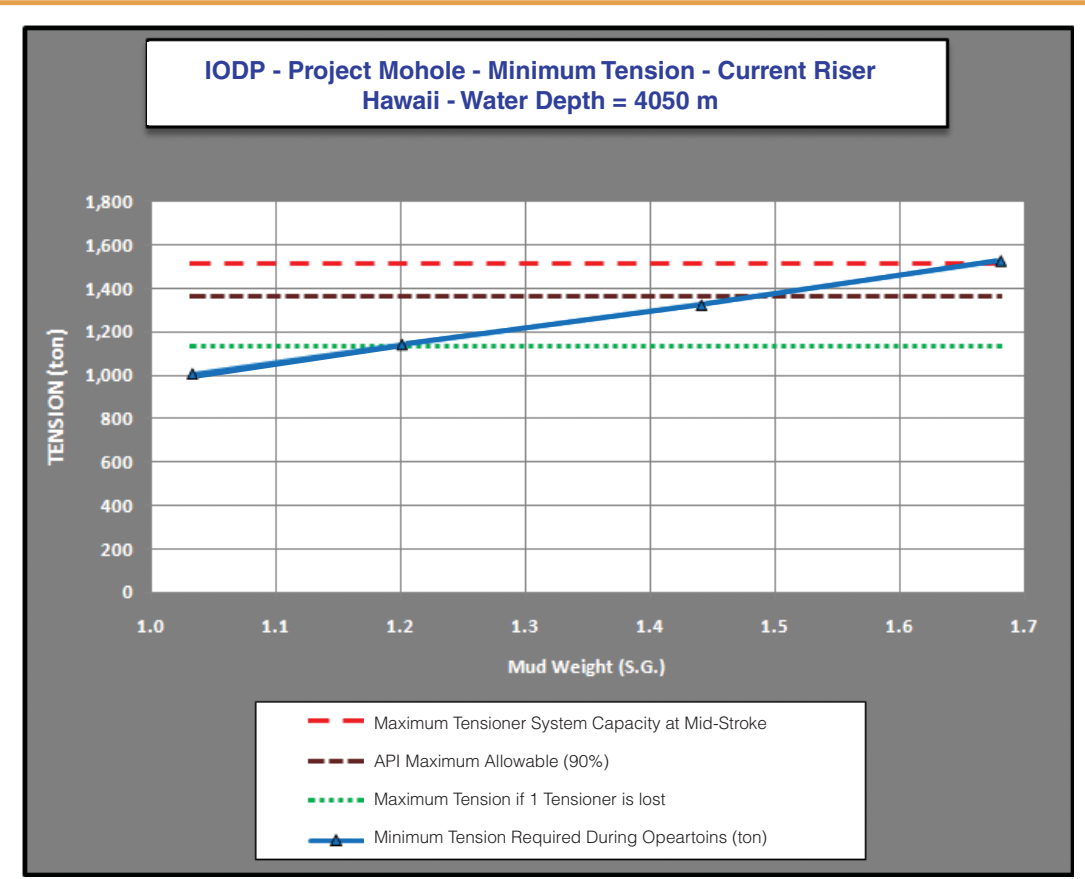

Figure 2. Riser tension requirements vs. mud weight for the current Chikyu drilling riser at the Hawaii location (Chikyu Spec. 2008.pdf).

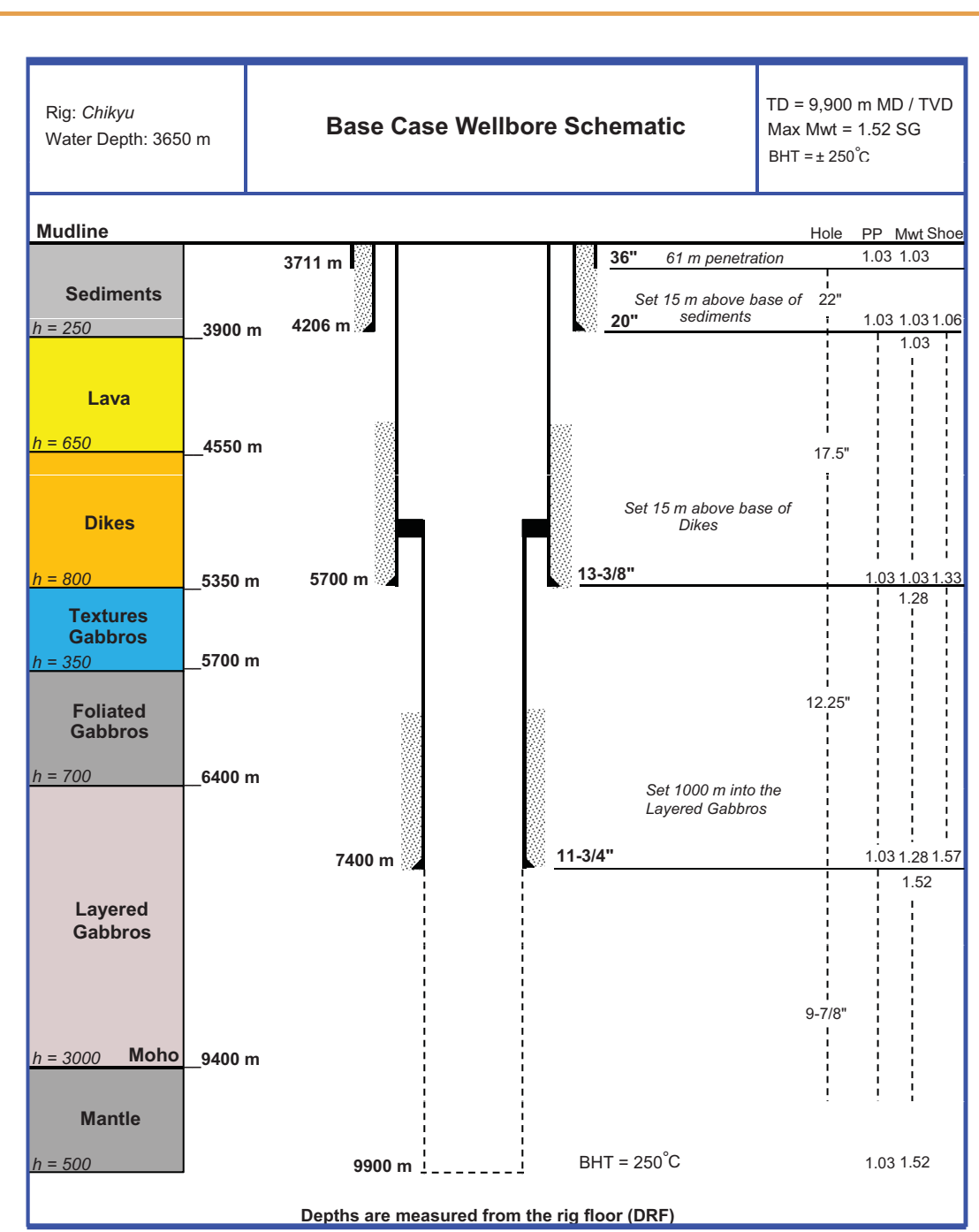

Figure 3. Base case wellbore configuration. 
combination of readily available oilfield drill pipe and the Chikyu's existing drill pipe. Therefore a non-standard, special high strength drill string is not needed.

Operational time estimates for four different scientific drilling cases were developed for each of the candidate locations (Table 1). Case 1 assumed that that the hole is continuously cored to total depth. Case 2 assumed long sections of continuous core are taken across the major lithologic and geophysical transition intervals of key sections. Case 3 assumed that only spot coring is done during the last $10 \mathrm{~m}$ of hole before each bit trip. And , Case 4 assumed that the hole is drilled to the Moho and that only the mantle is cored. Operations time curves were developed for each different case and location (Fig. 4). It was determined from this work that the time spent tripping for a new drill bit was as much as $40 \%$ of the overall operational time. The development of drill bits with enhanced operation hours will therefore have a tremendous impact on the time and cost it will take to drill/core the Moho well.

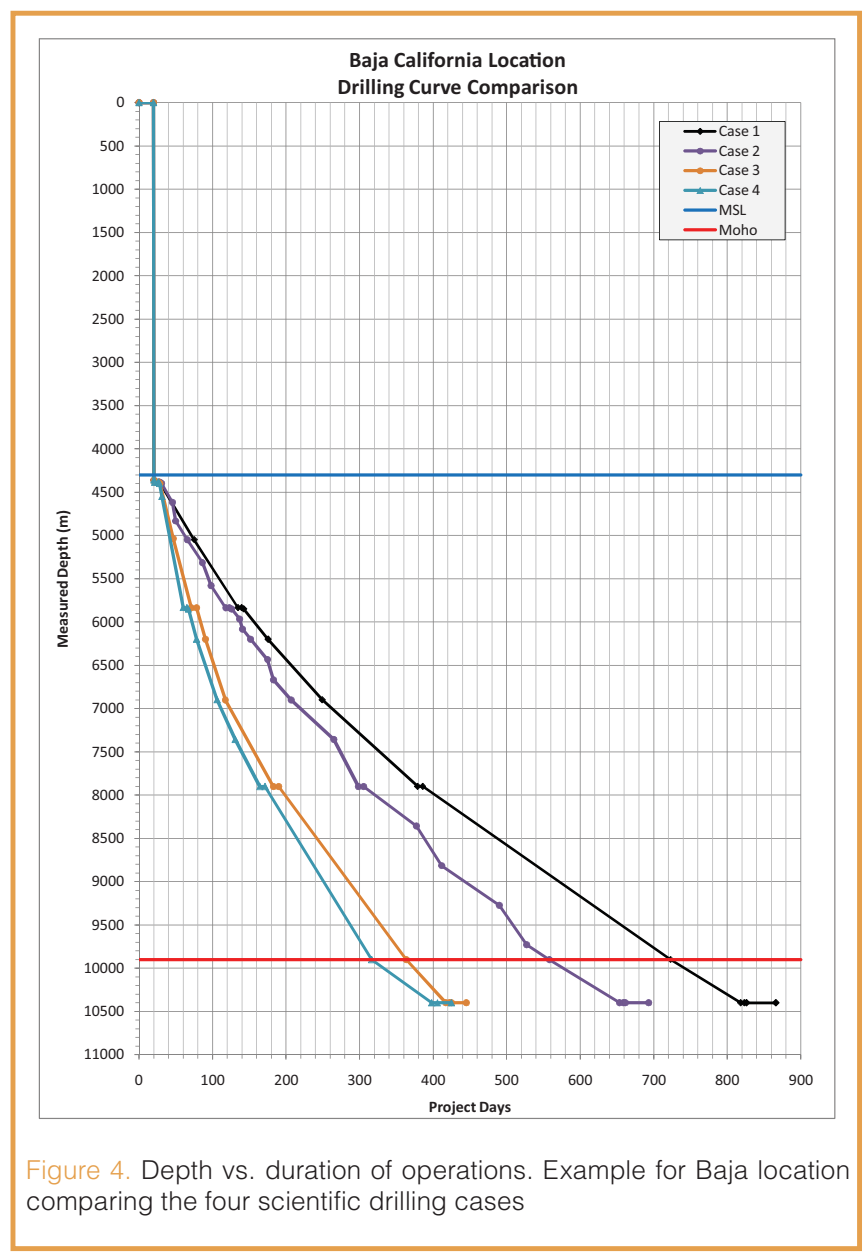

Table 1. Operational time estimates (based on current technologies).

\begin{tabular}{|c|c|c|c|c|c|}
\hline \multirow{2}{*}{$\begin{array}{l}\text { Candidate } \\
\text { Location }\end{array}$} & \multirow{2}{*}{$\begin{array}{c}\text { Water } \\
\text { Depth } \\
\text { (m) }\end{array}$} & \multicolumn{2}{|c|}{$\begin{array}{l}\text { Total Depth } \\
\text { Below }(\mathrm{m}) \text { : }\end{array}$} & \multirow{2}{*}{$\begin{array}{c}\text { Drill/ } \\
\text { Core } \\
\text { Time } \\
\text { (days) }\end{array}$} & \multirow{2}{*}{$\begin{array}{c}\text { Total } \\
\text { Project } \\
\text { Time } \\
\text { (days) }\end{array}$} \\
\hline & & $\begin{array}{l}\text { Rig } \\
\text { Floor }\end{array}$ & $\begin{array}{l}\text { Sea } \\
\text { Floor }\end{array}$ & & \\
\hline \multicolumn{6}{|l|}{ Cocos Location } \\
\hline Case 1 & 3650 & 9900 & 6250 & 696 & 756 \\
\hline Case 2 & 3650 & 9900 & 6250 & 564 & 617 \\
\hline Case 3 & 3650 & 9900 & 6250 & 433 & 480 \\
\hline Case 4 & 3650 & 9900 & 6250 & 374 & 418 \\
\hline \multicolumn{6}{|l|}{ Baja Location } \\
\hline Case 1 & 4300 & 10,400 & 6100 & 807 & 866 \\
\hline Case 2 & 4300 & 10,400 & 6100 & 642 & 693 \\
\hline Case 3 & 4300 & 10,400 & 6100 & 405 & 445 \\
\hline Case 4 & 4300 & 10,400 & 6100 & 386 & 425 \\
\hline \multicolumn{6}{|l|}{ Hawaii Location } \\
\hline Case 1 & 4050 & 10,750 & 6700 & 876 & 934 \\
\hline Case 2 & 4050 & 10,750 & 6700 & 688 & 737 \\
\hline Case 3 & 4050 & 10,750 & 6700 & 448 & 485 \\
\hline Case 4 & 4050 & 10,750 & 6700 & 422 & 443 \\
\hline
\end{tabular}

\section{Conclusions}

The results of this study show that drilling/coring a scientific hole into the upper mantle is certainly feasible, and that existing solutions are currently available to many of the technological challenges based on work being done in the oilfield and geothermal industries. In addition, technologies and techniques are continuously advancing and can be expected to continue to close the gap between what is required for the "Moho Project" and what is currently possible.

\section{References}

Alt, J.C., Teagle, D.A.H., Umino, S., Miyashita, S., Banerjee, N.R., Wilson, D.S., the IODP Expeditions 309 and 312 Scientists, and the ODP Leg 206 Scientific Party, 2007. IODP Expeditions 309 and 312 drill an intact section of upper oceanic basement into gabbros. Sci. Drill., 4:4-10. doi:10.2204/iodp.sd.4.01.2007

Pilisi, N., and Whitney, B., 2011. IODP - Project Mohole - Initial Blade Feasibility Study. Report to IODP by Blade Energy Partners, Frisco, Texas, 7 June 2011. Available online at http://www. iodp.org/weblinks/Featured-Publications-HOME-PAGE/ IODP-Project-MoHole-Initial-Feasibility-Study-PDF-

For full references, see the full report at http://www.iodp. org/weblinks/Featured-Publications-HOME-PAGE/I ODP-Project-MoHole-Initial-Feasibility-Study-PDF-

\section{Authors}

Nicolas Pilisi and Bill Whitney, Blade Energy Partners, 2600 Network Boulevard, \#550, Frisco, TX 75034-6036, U.S.A., e-mail: bwhitney@blade-energy.com, npilisi@bladeenergy.com. 